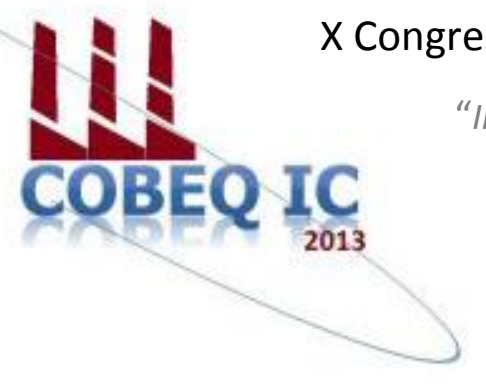

"Influência da pesquisa em Engenharia Química no desenvolvimento tecnológico e industrial brasileiro"

Universidade Federal Rural do Rio de Janeiro Universidade Severino Sombra Vassouras - RJ - Brasil

\title{
ELETROFLOCULAÇÃO EM EFLUENTESOLEOSOS UTILIZANDO ELETRODOS DE ALUMÍNIO
}

\author{
NASCIMENTO*1, I. L.; GOBBI' ${ }^{2}$ L. C.A.; PORTO³ ${ }^{3}$ P. S. S; ROCHA ${ }^{3}$, S. M. S. \\ ${ }^{1}$ Aluno do DETEC/UFES; ${ }^{2}$ Mestrando do PGEN/UFES ${ }^{3}$ Professor da DEQ/UFRRJ \\ Departamento de Engenharias e Tecnologia - Universidade Federal do Espirito Santo \\ Endereço-UFES, BR 101, km 60, São Mateus, CEP. 29.932-540, ES, \\ email: rochasms@gmail.com/sandra.m.rocha@ufes.br
}

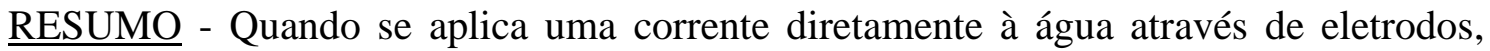
utilizando a técnica de eletrofloculação, a barreira de energia é superada e as moléculas de água são quebradas liberando $\mathrm{Al}^{3+}$ e hidrogênio desenvolvido no anodo e catodo respectivamente. $\mathrm{O}$ cátion do metal reage com o íon hidroxila, formando um hidróxido metálico que age como coagulante, que agregam as partículas poluentes que, dependendo da quantidade de bolhas geradas no cátodo, irão precipitar ou atingir a superfície. Neste estudo foi investigada a influência da variação da razão da área superficial dos eletrodos (SA), pelo volume do reator (V) na remoção de matéria orgânica do efluente, medida em forma de demanda química de oxigênio (DQO). O parâmetro AS/V foi escolhido por ser geralmente utilizado no escalonamento de reatores. Assim utilizou-se um reator de $3,5 \mathrm{~L}\left(3500 \mathrm{~cm}^{3}\right)$ e eletrodos de alumínio com área superficial de 24,5; 50 e $84 \mathrm{~cm}^{2}$. Após os testes pôde-se observar que, independente do parâmetro SA/V, ocorreu um acréscimo de $\mathrm{pH}$ e a "limpeza" da água, além disso, o eletrodo com maior área superficial propiciou a maior redução de carga orgânica em um tempo de retenção hidráulica de 30 minutos.
\end{abstract}

Palavras chave: Agua de produção de Petróleo, Teor de Óleos e Graxas, DQO

\section{INTRODUÇÃO}

Há pouco tempo a água deixou de ser considerada um bem inesgotável, pressionando o setor industrial a controlar o uso e a qualidade deste insumo. Apesar da consciência ambiental da população e a rigorosa legislação para descarte de efluentes, muitos aquíferos são constantemente poluídos, quer seja por esgotos domésticos ou efluentes industriais.
As indústrias, em seus processos produtivos, são as maiores geradoras de efluentes. Algumas como as indústrias têxtil, de papel e celulose e petroquímica, merecem destaque pelo vultoso volume de efluentes que são descartados diariamente por estas empresas. $\mathrm{Na}$ busca por se enquadrarem nas exigências legais, cada vez mais empresas investem no tratamento de efluentes, quer seja para descartar ou mesmo para a reutilização destas águas residuárias. 
No que tange a indústria de petróleo, em particular à produção offshore, os sistemas de tratamento de efluentes devem apresentar duas características principais, ser eficientes e compactos, haja vista que as plataformas possuem espaço reduzido para implementação de sistemas de tratamento de efluentes, bem como necessitam enquadrar seus efluentes nos limites de quantificação para o descarte em mar aberto ou reinjeção nos poços de petróleo.

$\mathrm{Na}$ busca por satisfazer a necessidade das indústrias petrolíferas várias técnicas de tratamento de efluentes têm sido estudadas, dentre elas a eletrofloculação.

O tratamento de efluentes via reação eletrolítica, constitui basicamente na passagem de corrente elétrica através de uma célula eletrolítica que está em contato com o efluente, propiciando duas operações distintas que acontecem em paralelo, a eletrocoagulação e a eletroflotação. Em que a primeira operação é responsável pela quebra da emulsão óleo-água seguida da coagulação das partículas, já a eletroflotação é responsável pelo arraste das partículas para a superfície (Cerqueira, 2006). Esta flotação ocorre porque as bolhas de ar que são formadas nos eletrodos adsorvem as partículas presentes no efluente ocasionando assim a formação de duas fases no efluente devido à diferença de densidade da fase contínua e da fase dispersa (Figura 1).

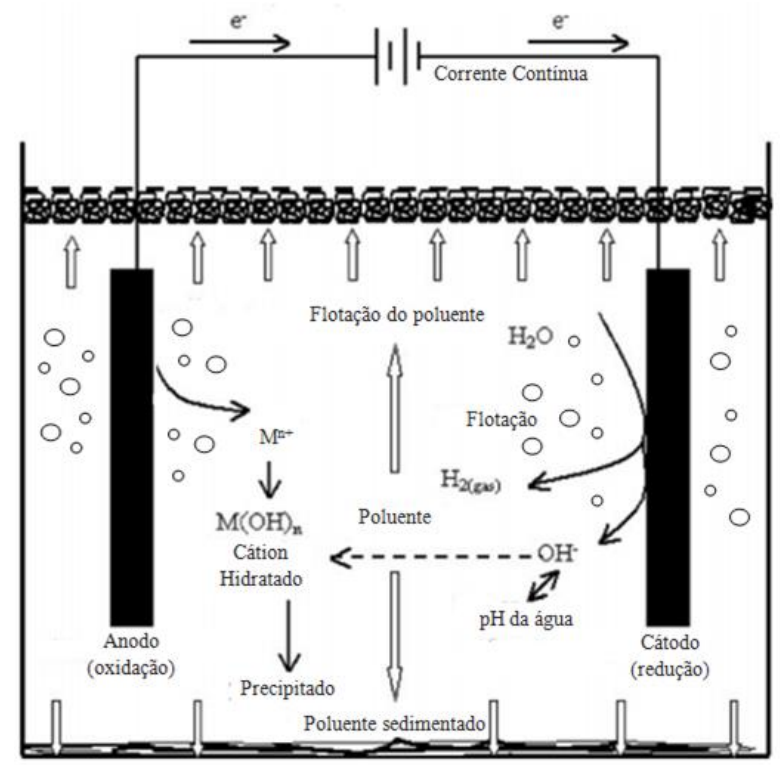

Figura 1 - Diagrama esquemático de uma célula de eletrocoagulação de dois eletrodos de escala de bancada. Fonte: Adaptação de Mollah et al. (2004).
Devido à simplicidade de operação e da diversidade de efluentes que podem ser tratados pela eletrofloculação, esta técnica vêm ganhando espaço nas estações de tratamento de efluentes (ETE) por remover partículas coloidais de pequenos diâmetros, pois o campo elétrico aplicado consegue promover com maior rapidez o contato entre as partículas, facilitando a coagulação. Utilizando o campo elétrico para a formação dos coloides, se elimina a adição de produtos químicos usualmente utilizados nesta etapa do tratamento, o que torna esta técnica ainda mais interessante (Crespilho, 2004).

Neste contexto, este trabalho objetiva identificar qual a melhor relação área superficial do eletrodo pelo volume do reator (AS/V) para o tratamento de água de produção de petróleo utilizando eletrodos de alumínio.

\section{MATERIAIS E MÉTODOS}

O efluente utilizado nos testes experimentais foi produzido no laboratório, ou seja, de origem sintética. Optou-se por utilizar o efluente sintético visando minimizar as interferências dos constituintes da água de produção na analise dos resultados, visto que a água de produção de petróleo é muito complexa. Para a produção do efluente sintético, a cada $2 \mathrm{~L}$ de água foram adicionados $0,4 \mathrm{~g}$ de óleo leve, $24 \mathrm{~g}$ de $\mathrm{NaCl}$ e $0,04 \mathrm{~g}$ de emulsificante comercial (EMUSTAB da marca Selecta), para garantir a formação da emulsão, o efluente foi submetido a uma agitação vigorosa de $11000 \mathrm{rpm}$ em aparelho tipo turrax, modelo T25 basic da marca IKA Laboratechnik durante 18 minutos.

Os testes de separação água/óleo foram realizados em um reator eletrolítico de $3,5 \mathrm{~L}$ de volume útil, sendo que a capacidade total do reator é de 4L (Figura 2). No reator foram colocadas duas torneiras para a retirada das amostras no tempo pré-determinado.

Os experimentos foram realizados em batelada de forma se determinar o tempo de detenção hidráulica (TDH) necessário para a separação da emulsão óleo/água utilizando eletrodos de alumínio. Os eletrodos testados neste estudo possuíam as seguintes dimensões, eletrodo A $(7 \mathrm{~cm} \mathrm{X} 3,5 \mathrm{~cm} \times 0,2 \mathrm{~cm})$; eletrodo

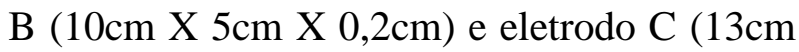


$X \quad 6,5 \mathrm{~cm} \quad X \quad 0,2 \mathrm{~cm}) . \quad$ Foi utilizado um espaçamento de $0,5 \mathrm{~cm}$ entre cada placa paralela, distância considerável para propiciar uma boa floculação. Os eletrodos utilizados neste trabalho estão apresentados na Figura 3.

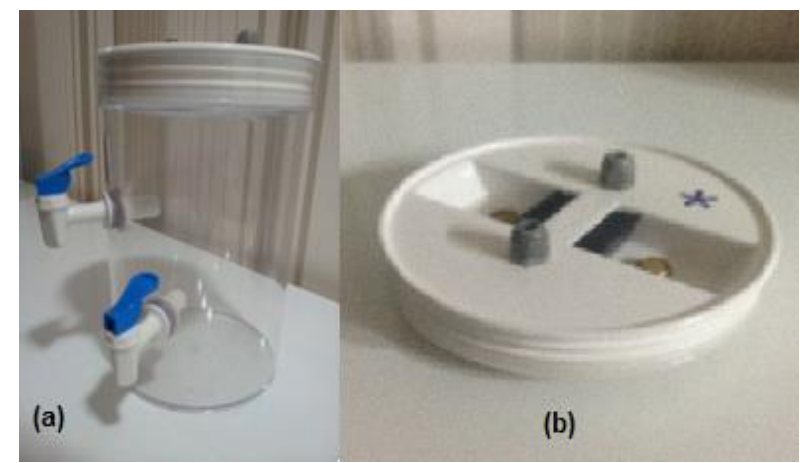

Figura 2- Reator eletrolítico(a); Tampa do reator $(b)$

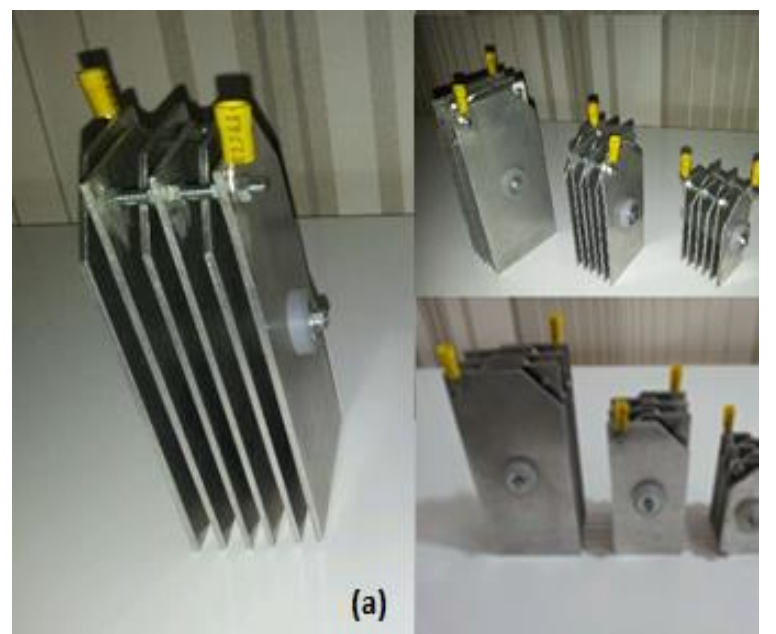

Figura 3: Fotografia dos eletrodos: a) Vista lateral b) Vista diagonal C) Vista frontal dos eletrodos

Como o parâmetro utilizado para o scalup de reatores eletrolíticos é a razão entre a área superficial dos eletrodos (AS) e o volume do reator (V). Foi calculado o parâmetro (AS/V) de cada eletrodo, visto que o volume útil do reator não alterou de um teste para o outro. Assim doravante, quando se falar em eletrodo A, B e C, entende- se AS/V de 7; 14,28 e $24 \mathrm{~cm}^{2} / \mathrm{L}$ respectivamente.

De forma a se determinar o tempo de detenção hidráulica do efluente no reator eletrolítico foi realizado um teste de redução da DQO (Demanda Química de Oxigênio) em função do tempo para os três eletrodos, durante os testes o eletrodo foi ligado a uma fonte e a um alternador de polaridade, para evitar o desgaste dos eletrodos e o volume de efluente foi fixado em 3,5 L, o desenho esquemático dos sistema utilizado na realização dos testes, está mostrado na Figura 4.

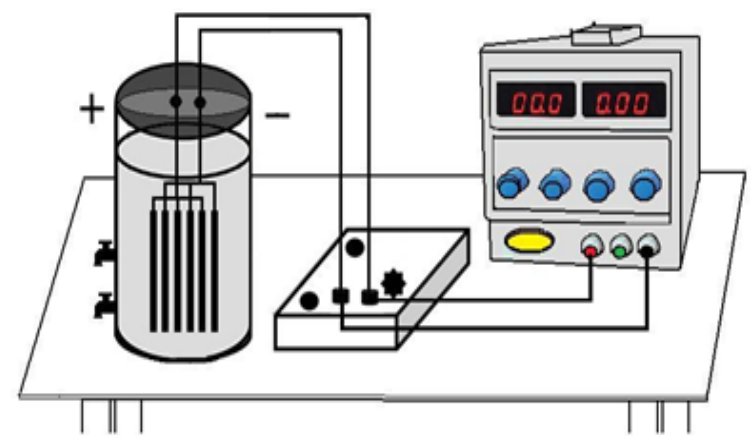

\section{Figura 4 - Desenho esquemático do sistema utilizado nos testes de eletrólise}

Após determinar o TDH comum aos três eletrodos foram realizados testes para se determinar a eficiência de redução da concentração da matéria orgânica através da Demanda Química de Oxigênio (DQO) em função do tempo de operação do reator, visando determinar o melhor reator a ser empregado nos testes de eletrolise.

De posse da melhor relação AS/V foram realizados os testes de redução de carga orgânica e teor de óleos e graxas óleos e graxas do efluente. As análises físico-químicas foram realizadas de acordo com as metodologias Standard Methods (2005).

\section{RESULTADOS E DISCUSSÕES}

$\mathrm{Na}$ Figura 5 estão apresentados os valores de DQO em função do tempo de eletrolise para os três eletrodos estudados, de forma a se determina o TDH de operação do reator eletrolítico.

A partir dos valores de DQO obtidos durante os 90 minutos de operação do reator, foi possível observar que até os 30 minutos de operação ocorreu uma redução da DQO das amostras para os 3 eletrodos estudados, porém, após este tempo os valores voltaram a subir.

Esta baixa velocidade de redução da demanda química de oxigênio observada entre 15 e 30 minutos de eletrolise deve ter ocorrido devido à baixa concentração de matéria orgânica no reator, ou seja, se este sistema estivesse funcionando de forma contínua as 
moléculas de efluentes alimentadas deveriam permanecer em média 20 minutos no reator. Assim, após 30 minutos não existia mais moléculas de óleo para se associarem aos flocos de alumínio formados e estes não foram arrastados para a superfície, ficando disperso no efluente clarificado, sendo coletado juntamente com as amostras, causando interferências nas analises que apresentaram aumento de DQO a partir deste tempo de eletrolise.

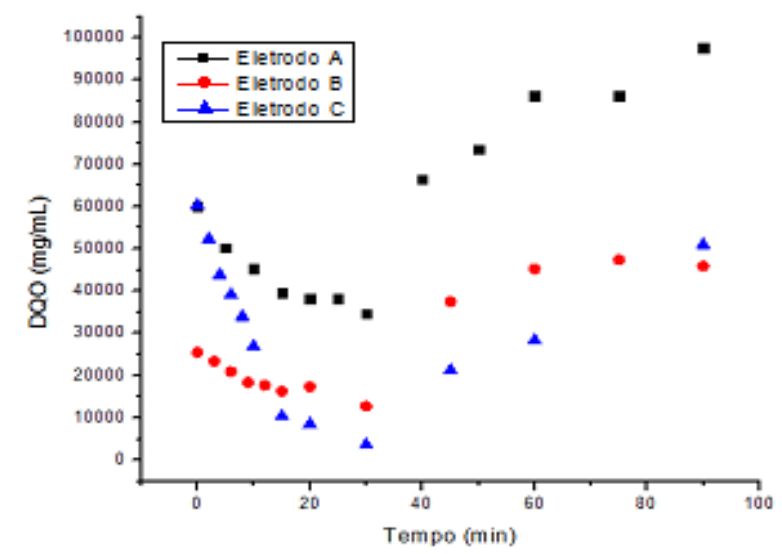

Figura 5: Curva da redução de DQO em função do tempo

Durante os testes para os 3 eletrodos, a estabilidade do $\mathrm{pH}$ ocorreu em torno do $\mathrm{pH}$ 9, porém o tempo para a estabilização do $\mathrm{pH}$ diminuiu com o aumento da relação AS/V (Figura 6).

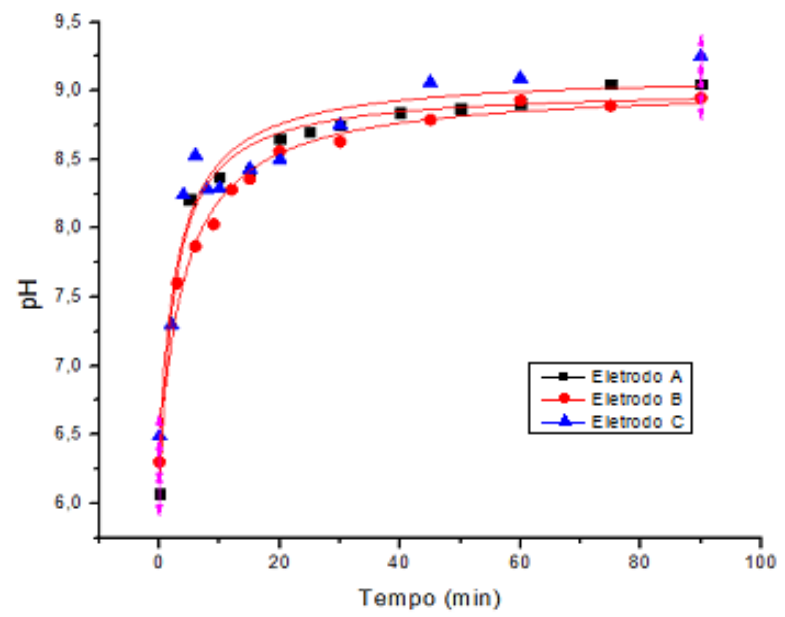

Figura 6: Curva dos valores de pH durante a eletrolise

Este fenômeno do aumento do $\mathrm{pH}$ em função do tempo de operação do reator pode ser explicado pelo desprendimento de $\mathrm{Al}^{3+}$ da célula eletrolítica durante sua operação, tornando o meio mais básico com o passar do tempo. Portanto, nos eletrodos de maior área superficial ocorreu um maior desprendimento de $\mathrm{Al}^{3+}$, tornando, em um menor intervalo de tempo, o meio mais básico. A partir, portanto, da análise do tempo que cada eletrodo levou para atingir a estabilidade do $\mathrm{pH}$, comprova-se que o eletrodo $\mathrm{C}$, que possui a maior área superficial estudada, apresentou o menor tempo para a estabilização do $\mathrm{pH}$.

$\mathrm{O} \mathrm{R}^{2}$ do gráfico $\mathrm{pH}$ versus tempo do eletrodo A é igual a 0,$98293 ; 0,98804$ para o eletrodo B e 0,91235 para o eletrodo C, o que mostra que para os dois primeiros eletrodos, mais de $98 \%$ das amostras se ajustaram no modelo exponencial, enquanto para o último eletrodo, mais de $91 \%$ das amostras puderam ser ajustadas por este modelo.

Após a determinação do TDH foram realizados os testes de eletrofloculação para os três eletrodos de forma a se analisar o percentual de remoção de DQO e assim, determinar a melhor relação AS/V para o tratamento do efluente estudado. Estes valores podem ser observados na Figura 7.

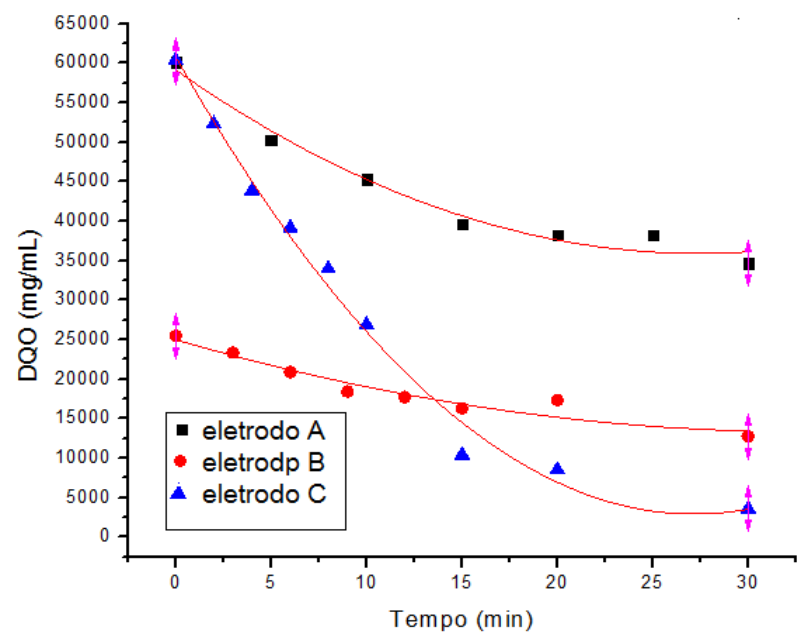

\section{Figura 7: Curva da eficiencia de remoção de DQO em função do tempo para o eletrodo A, B e C}

Para o eletrodo A, o ajuste polinomial apresentou um $\mathrm{R}^{2}$ de 0,96681 mostrando que o mesmo é um bom ajuste para a curva, onde apenas 3,32\% das amostras não seguiram o modelo exponencial. Tem-se que a redução da carga orgânica durante os 30 minutos de operação foi de $42,33 \%$.

Para o eletrodo $\mathrm{B}$, o $\mathrm{R}^{2}$ obtido através do ajuste polinomial foi de 0,91105 , que está 
dentro do aceitável para análise experimental, com 8,9\% das amostras desviadas do modelo polinomial. Para este eletrodo, a redução da carga orgânica durante o tempo de operação do reator foi de cerca de $50 \%$. A redução da carga orgânica do eletrodo $B$ foi maior do que a redução do eletrodo A por volta de $8 \%$. Este fato ocorre justamente pela maior relação $\mathrm{AS} / \mathrm{V}$, onde no eletrodo $\mathrm{B}$, a área superficial em contato com o efluente a ser tratado é maior, proporcionando, no mesmo intervalo de tempo, um maior desprendimento de bolhas que carreiam o óleo da emulsão óleo/água, ocasionando assim em uma maior eficiência.

Para a relação de AS/V igual a 24 $\mathrm{cm}^{2} / \mathrm{L}$, eletrodo $\mathrm{C}$, o gráfico de ajuste polinomial possui $\mathrm{R}^{2}$ igual a 0,98852 , mostrando-se dentre os demais eletrodos, o de melhor ajuste polinomial, com apenas 1,15\% das amostras não seguindo o modelo exponencial. Além de se ajustar melhor ao modelo este eletrodo também propiciou a maior redução de DQO (94\%), valor este que é superior ao exigido pela legislação Federal para descarte.

Este resultado era de se esperar, a partir da análise de que quanto maior a área superficial do eletrodo, maior é a quantidade de bolhas desprendidas do mesmo, ocasionando um maior carreamento de óleo da emulsão óleo/água, aumentando assim, a eficiência e a rapidez da separação do poluente

A Figura 8 mostra o reator eletrolítico operando com o eletrodo C. Na Figura 6 (a) água oleosa sem tratamento, (b) após 5 min de eletrólise e (c) no fim da reação (30 min).

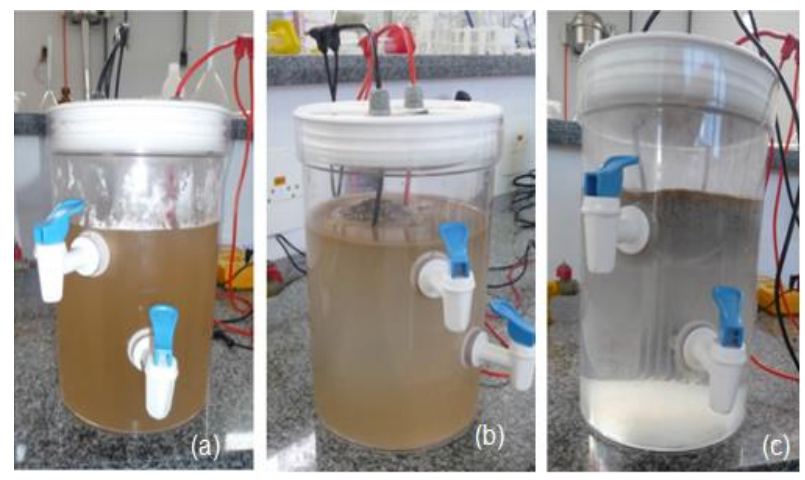

Figura 8: Fotos do reator eletrolítico em diferentes tempos de tratamento de operação

Como o eletrodo $\mathrm{C}$ apresentou melhor resultado entre os demais, foi realizado o Teor de óleos e graxas (TOG) para este eletrodo. Os testes de redução do TOG foram realizados com o objetivo de averiguar se o efluente se enquadraria nos limites estabelecidos pela legislação federal, para descarte ou para reinjeção em poços de produção.

A Figura 9 mostra a redução da concentração de óleo com o tempo de eletrólise para o eletrodo C. É possível observar que houve uma redução superior a $80 \%$ da concentração de óleo presente no efluente. Essa remoção mostra o quão eficiente o eletrodo $\mathrm{C}$ foi em sua operação, visto que além de superar a redução de matéria orgânica exigida na legislação, o mesmo apresentou uma boa remoção teor de óleos e graxas.

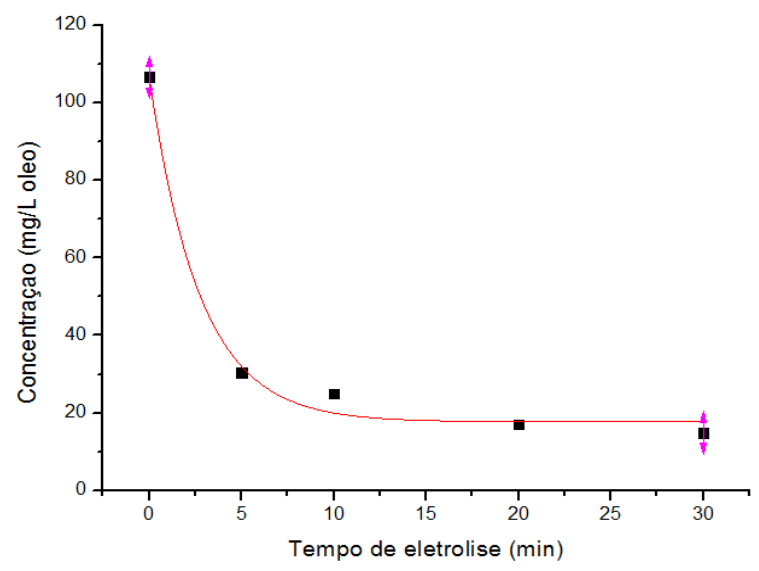

Figura 9: Gráfico da remoção do TOG versus o Tempo de eletrólise.

Na Figura9 verifica-se um decréscimo significativo no valor do TOG, logo nos primeiros cinco minutos de eletrólise. Isto provavelmente ocorreu devido ao grande volume de microbolhas geradas tanto no ânodo quanto no cátodo, que fluem de forma ascendente até a superfície arrastando as moléculas de óleo para a superfície. Este deslocamento faz com que ocorra a flotação das partículas e impurezas em suspensão e, principalmente, do material oleoso presente. Ao final da eletrólise a água apresentou uma concentração média de óleos e graxas de 6,01 $\mathrm{mg} / \mathrm{L}$. Valor este que está bem abaixo do exigido pelo CONAMA 257/2005, que exige a concentração máxima para descarte de $20 \mathrm{mg} / \mathrm{L}$, e atende às exigências para a reinjeção em poços de produção.

Na Figura 10 é possível visualizar a lama (flocos de alumínio + óleo), formada na 
superfície do reator eletrolítico ao fim de 30 minutos de eletrólise.

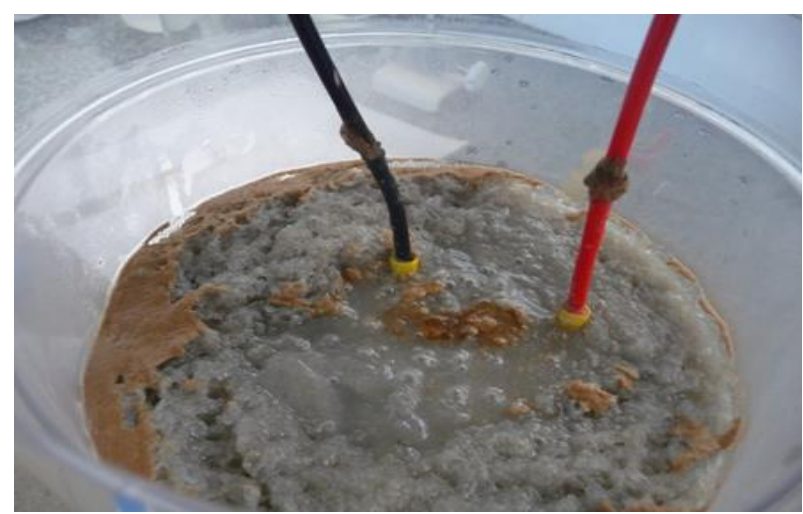

Figura 9 - Foto da lama gerada durante a eletrofloculação

\section{CONCLUSÃO}

A partir dos resultados obtidos neste trabalho, em escala de bancada, foi possível concluir que para os três eletrodos o tempo de detenção hidráulica foi de 30 minutos e que o $\mathrm{pH}$ do efluente para os três eletrodos tendeu à estabilização em torno de $\mathrm{pH}$ 9. Dentre os eletrodos utilizados, o eletrodo $\mathrm{C}$, de área superficial $84 \mathrm{~cm}^{2}$ e razão área superficial por volume igual a $24 \mathrm{~cm}^{2} / \mathrm{L}$ foi o que apresentou melhores resultados em termos de redução percentual da carga orgânica do efluente (94\%). Este eletrodo também apresentou valores significativos na redução do TOG em torno de $80 \%$.

Podendo assim concluir que é possível utilizar a técnica de eletrofloculação no tratamento de água produzida de petróleo, visto que os valores finais de DQO e TOG no efluente tratado atendem às exigências legais da legislação federal, para o descarte do efluente no mar. Por ser uma técnica eficiente e demandar pouco espaço para sua instalação. A energia necessária para os eletrodos pode ser de fontes fotovoltaicas.

\section{REFERÊNCIAS}

APHA. "Standard Methods for Examination of Water and Wastewater." 20. Ed. Washington: American Public Health Association, 1998.
CERQUEIRA, A. A. “Aplicação da técnica de eletrofloculação no tratamento de efluentes têxteis." Rio de Janeiro: Universidade do Estado do Rio de Janeiro, 2006. 111 p. Dissertação (Mestrado).

CRESPILHO, F. N.; REZENDE, M. O. O. "Eletroflotação: Princípios e Aplicações." São Carlos: Editora Rima, 2004. 96 p.

CONAMA, Conselho Nacional do Meio Ambiente. "Resolução 357 de 17 de Março de 2005".

OLIVEIRA, R.C.G. "Estudos de variáveis operacionais e interfaciais na flotação de óleo por gás dissolvido." Dissertação (Mestrado em Engenharia), COPPE/UFRJ, Rio de Janeiro. 1995.

STEPHENSON, M.T. "A Survey of Produced Water Studies." In Produced Water, J.P. Ray and F.R. Englehart (eds.), Plenum Press, New York. 1992.

THOMAS, J. E. "Fundamentos de Engenharia de Petróleo." PETROBRAS, Rio de Janeiro, 2001.

\section{AGRADECIMENTOS}

Os autores agradecem ao $\mathrm{CNPq}$ pela concessão da bolsa de iniciação científica e a Universidade Federal do Espírito Santo pela infraestrutura necessária para a realização do trabalho. 